\title{
Identifying Urban Residents' Activity Space at Multiple Geographic Scales Using Mobile Phone Data
}

\author{
Lunsheng Gong ${ }^{1,2}$, Meihan Jin ${ }^{3,4}\left(\mathbb{O}\right.$, Qiang Liu ${ }^{3,4}$, Yongxi Gong ${ }^{3,4, *(1)}$ and Yu Liu ${ }^{5}(1)$ \\ 1 Laboratory for Urban Future, Peking University (Shenzhen), Shenzhen 518055, China; \\ Clarence0201@pku.edu.cn \\ 2 School of Urban Planning and Design, Peking University Shenzhen Graduate School, \\ Shenzhen 518055, China \\ 3 Shenzhen Key Laboratory of Urban Planning and Decision Making, Harbin Institute of \\ Technology (Shenzhen), Shenzhen 518055, China; jinmeihan@hit.edu.cn (M.J.); aliceliu618@sina.com (Q.L.) \\ 4 School of Architecture, Harbin Institute of Technology (Shenzhen), Shenzhen 518055, China \\ 5 Institute of Remote Sensing and Geographical Information Systems, School of Earth and Space Sciences, \\ Peking University, Beijing 100871, China; liuyu@urban.pku.edu.cn \\ * Correspondence: gongyx@hit.edu.cn; Tel.: +86-755-26035011
}

Received: 26 February 2020; Accepted: 10 April 2020; Published: 12 April 2020

\begin{abstract}
Residents' activity space reflects multiple aspects of human life related to space, time, and type of activity. How to measure the activity space at multiple geographic scales remains a problem to be solved. Recently, the emergence of big data such as mobile phone data and point of interest data has brought access to massive geo-tagged datasets to identify human activity at multiple geographic scales and to explore the relationship with built environment. In this research, we propose a new method to measure three types of urban residents' activity spaces-i.e., maintenance activity space, commuting activity space, and recreational activity space-using mobile phone data. The proposed method identifies the range of three types of residents' activity space at multiple geographic scales and analyzing the relationship between the built environment and activity space. The research takes Zhuhai City as its case study and discovers the spatial patterns for three activity space types. The proposed method enables us to achieve a better understanding of the human activities of different kinds, as well as their relationships with the built environment.
\end{abstract}

Keywords: activity space; multiple geographic scales; mobile phone data; point of interest; anchor point

\section{Introduction}

Activity space is the term geographers usually use to describe the set of locations with which a person has direct contact during daily activities [1], mainly including residences, workplaces, and daily shopping sites. It represents the space and time costs to fulfill the necessities of life and plays an important role in revealing the living quality of citizens. This important geographical concept has been widely used in accessibility measurement for public facilities [2,3], social division [4], and personal risk $[5,6]$.

The time geography theory emphasizes that people's travel behaviors are mainly constrained by time and space, and indicates that daily activities usually involve a certain size of space in a certain amount of time [7]. Dwelling, transportation, work, and recreation are the four functions of the city mentioned in the Charter of Athens [8], and transportation is usually the link between different activities. Thus, daily activities in cities can be divided into dwelling, work, and recreation. Researchers have discovered that the size of activity space usually varies for different activity purposes. For instance, 
working activity is usually associated with a bigger space than maintenance activity. Handy et al. demonstrated that non-work trips depend more on the neighborhood scale characteristics [9]. Similarly, Yang et al. believe that the fit scale for subsistence trips is a traffic analysis zone (TAZ) and a $600 \mathrm{~m}$ buffer, and the suitable scales for maintenance and recreation activities should be $250 \mathrm{~m}$ and $1500 \mathrm{~m}$ buffers [10]. These studies indicate that, for studying different activities, the geographic scales should be set independently according to the activity purposes.

Geographic scale is a graduated range of spatial values forming a standard geographical system for measuring or grading something. For residents, activity spaces of different geographic scales have the same center-residence. In the anchor point theory, the resident's activity takes place around some anchor point, such as a residence, working place, or shopping mall, and a residence is the most important anchor point in a resident's daily life [11]. Although there is an argument that activity space is polycentric (residence and workplace) [12], the residence is the main center of human trajectory [13].

Activity space can be determined by the built environment that meets their daily activity needs [1]. The built environment is the human-made space in which people live, work, and recreate on a day-to-day basis, including buildings, land uses, transportation systems, and other spatially related elements [14]. Most of the existing researches focus on the impact on travel behaviors [15-17], and the built environment influence on travel distance had drawn special attention from scholars [18-20]. They discovered that, for different travel behavior, the influence from different built environment varies. For example, the increase in land use diversity [21] and residence density [22,23] can reduce car commuter possibility and distance, and areas with high employment opportunities will lead people to choose to work nearby [24], which means less commuting distance [23]. Humans are more engaged in maintenance activities with higher-density or more diverse neighborhoods [25]. As travel behavior is one of the major urban activities and can link the activity destination in urban space, the built environment can also influence the activity space. As far as we know, different types of travel behavior performed in the built environment at multiple scales in space have not been deeply discussed in the existing research. In addition, existing studies mostly adopt a limit number of travel records to explore the relationship between the built environment and travel behavior and ignore the activity space formed by long-term behavior.

Recently, the emergence of big data has resulted in a massive number of geo-tagged datasets. These geo-tagged datasets can represent urban residents' travel behavior completely, providing new opportunities to observe activity space. Mobile phone datasets can be used for understanding the mobility of urban residents [26], estimating population distribution [27] and revealing mobility indicators of activity space [28]. Moreover, comprehensive and long-term mobile phone data was confirmed to be able to analyze the distribution of activity space [29].

As we mentioned above, most existing studies often focused on a certain type of activity, not emphasizing the multiple scales characteristics of residents' daily activities. Therefore, activity space has not been identified effectively at multiple geographic scales. The comparative study of different activity spaces, whether size or influence factor of it, is insufficient. In order to fill these gaps and improve the research on activity space, we proposed a new method to measure three types of urban residents' activity spaces at multiple geographic scales using mobile phone data in the study. By applying the method, we demonstrated the spatial-temporal distribution of the residents' activity and analyzed the relationship between urban residents' activity spaces and built environment factors in Zhuhai. The contribution of this study is to provide an efficient method for measuring the human activity space at multiple geographic scales and revealing the detailed relationship between various activity spaces and built environment factors.

The remainder of this paper is organized as follows. Section 2 introduces the brief information about the study area and datasets. Section 3 proposes the method for identifying urban residents' activity space, including the measurement of three types of activity spaces and the built environment factor definitions. Section 4 reports a case study in Zhuhai, applying a series of analyses using multiple linear regressions. The case study shows that the size of activity space is highly correlated with the 
spatial distribution of built environment factors. In Section 5, we draw some conclusions and introduce future work.

\section{Study Area and Datasets}

\subsection{Study Area}

The study area in this research is Zhuhai, as shown in Figure 1, located in south China, adjacent to the north of Macao. Zhuhai is one of the Special Economic Zones in southern China. According to a recent census, Zhuhai has a population of approximately 1.77 million residents in an area of approximately $1700 \mathrm{~km}^{2}$. There are three districts named Xiangzhou, Doumen, and Jinwan in Zhuhai. Among those districts, Xiangzhou is the most developed district, with abundant human activities and diverse built environments.

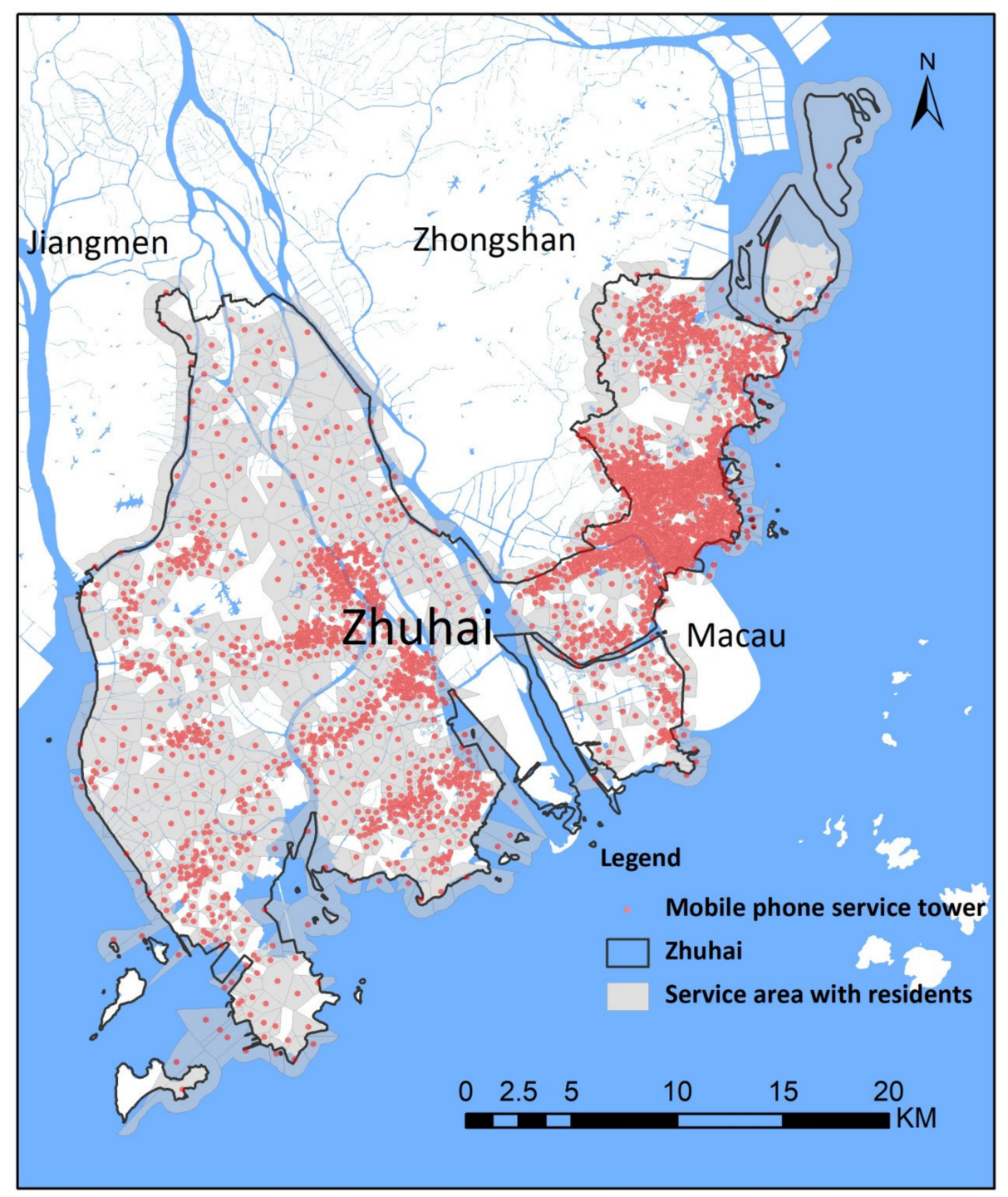

Figure 1. Study area and mobile phone service towers.

\subsection{Datasets}

The individual's spatial position in continuous time is necessary for measuring the scope of the activity space. The high precision of the mobile phone data enables extracting the activity trajectory [30] and characterizing the activity space. 
China Mobile Communications Group Co., Ltd. (CMCC) is the largest communication service provider in China. Mobile phone data records the location of each phone user (represented as the connected service tower location) in a time interval when a mobile phone was being used every day in April 2016. The mobile phone data includes user ID, the timestamp and the ID of service tower where the phone connects to. This dataset consists of 3363 service towers in total in Zhuhai (Figure 1). All the signals are recorded in the dataset despite the types (such as $2 \mathrm{G}, 3 \mathrm{G}$, or/and $4 \mathrm{G}$ ). If the connection distance of the service tower is not different and there is no terrain fluctuation, the mobile phone will connect to the nearest service tower. In Thiessen polygons, the nearest center of each point always belongs to the polygon where the point is located. Because of this characteristic, creating Thiessen polygons can make location information more accurate and has been a widely used division method when working with mobile phone data $[27,28]$. In order to protect users' privacy, no personal information, such as phone number, user's name, and identity number, is accessible during all the data processing procedures, and the location data is aggregated into the spatial unit that shaped by creating the Thiessen polygons.

Mobile phone data comes from CMCC's information system. In mobile phone data preprocessing, the system used Structured Query Language (SQL) in the relational database to extract the main stopover points of each user. The system resamples the trajectories of each user every 30 minutes, taking the position of the stopover point with the longest stay time as the users' representative stopover point in the 30 minutes. There are 48 main stopover points for one user in one day. In this paper, the dataset record people's trajectories in the form of the main stopover point every day in April 2016. The main stopover points will be used to determine the residence location and identify the activity space.

As the main material carrier of space in residents' daily lives, the built environment refers to an artificial environment for human activities [31], including various buildings, parks, transportation facilities, and so on. Point of Interest (POI) data is able to objectively describe built environment in general in an urban area, which has been proved more suitable than traditional land use data to explore the relationship between the built environment and human activity [32]. Moreover, POI data contains information about built environment and also includes the interest of human activity. Therefore, we choose POI dataset to represent the spatial distribution of the land use functions. The POI dataset in this study is provided by Gaode Maps and contains 117,059 POIs that belong to 15 subcategories of six primary categories. Table 1 shows the corresponding numbers of POIs in the 15 categories. Another built environment dimension concerned in this research is the transportation facility distribution. The road network can reflect the main structure of the transport facility distribution in Zhuhai given that the railway intra-urban transportation doesn't exist yet. The road network dataset consists of main roads in Zhuhai, and the total length is about $3000 \mathrm{~km}$. Main road structure can influence accessibility to human activity locations and travel behavior dramatically. So we consider the transportation structure as a major characteristic for understanding the relationship between human activity space and the built environment. 
Table 1. Categories and numbers of Points of Interest (POIs).

\begin{tabular}{ccc}
\hline Primary Categories & Subcategories & Numbers \\
\hline & Catering & 19,242 \\
Consumption & Shopping & 37,745 \\
& Recreation & 2652 \\
& Accommodation & 2213 \\
& Comprehensive & 18,812 \\
\hline Corporation & Corporation & 17,000 \\
\hline \multirow{2}{*}{ Public service } & Government and social groups & 3494 \\
& Park and square & 573 \\
& Public facility & 671 \\
Traffic & Hospital and pharmacy & 3394 \\
\hline \multirow{2}{*}{ Education } & Transportation facility & 4416 \\
\hline Residence & Educational and scientific & 3555 \\
\hline
\end{tabular}

\section{Methodology}

\subsection{Activity Space}

The four functions of the city mentioned in the Charter of Athens are dwelling, recreation, work, and transportation [8], and they can also represent the main activities of modern urban residents. Dwelling is a generalized concept that contains cooking, cleaning, shopping, and other activities taken for the maintenance of the household [33]. In this paper, the activity related to the dwelling is defined as maintenance activity. The most frequent transportation of modern urban residents is a round trip between residence and working location. In this research, we take transport to work as part of working activity and define it as commuting activity. Overall, maintenance, commuting, and recreation have been taken as the three main types of activities in urban residents' lives.

According to the anchor point theory, home is the most important anchor point in one's daily life [11]. Around the home position, the workplace and shopping sites are at the second importance level. Based on the anchor point, people gradually explore the surrounding environment and form their activity space. The process of carrying out physiologically necessary activities around the home forms the maintenance activity space. Due to the agglomeration of land use functions, the workplace is often far from home, which separates employment and residence. Commuting activity space is formed by commuting activity between home and working place. Generally, except for living and working, residents also have needs for leisure activities, and various types of leisure places form recreational activity space. Leisure activity frequency is usually less than other types of activities.

Meanwhile, some scholars believe that the geometry, size, and internal structure of activity spaces are affected by three major determinants: home, regular activities and movements between the centers of daily life [1,34]. In detail, "home" stands for a series of activities around the residence. The "regular activity" usually refers to working or going to school, and the "movements between the centers of daily life" refer to commuting between home and regular activity locations. This means that activity space is supposed to be decided according to two main types of activities: maintenance and commuting. From this perspective, urban residents' activity space can be generally divided into two scales based on spatial differences in activity types: one is the surrounding area of living house representing the maintenance activity space; the other is the commuting activity area that covers the home, workplace, and commuting route. Recreational activity is also significant to modern society. With the upgraded life quality, it plays an increasingly prominent role in residents' live quality as the economy keeps developing. The three main types of activities (maintenance, commuting, and recreational) together determine the activity space of urban residents, and three different scales of activity spaces are formed according to the spatial requirements of different activities. 
Due to the different semantics of the three activity types, the accessibility to destination varies significantly. Maintenance activity is the activity to fulfill basic living needs around the residence. Commuting activity is the activity of going to the workplace or study place and completing corresponding duties. Recreational activity contains a wider range of activities, including entertainment, visiting friends, etc. Normally, maintenance activity's scale is the smallest among the three and is mainly around the residence [11]. The job-housing imbalance in most cities today leads to longer commuting distance, so the commuting activity scale is much larger than that of the maintenance activity. The data extracted from the household travel survey provided by Zhuhai Institute of Urban Planning and Design confirms the proposed size difference between the commuting activity space and the maintenance activity space. The average radius of maintenance activity is $1.759 \mathrm{~km}$ and is much smaller than that of commuting activity, which is $4.002 \mathrm{~km}$. This further proves that the definitions of the space size of maintenance and commuting activity spaces are reasonable. The scale of recreational activity is slightly larger than commuting activity because recreational activity contains many different subcategories, and the destinations of them are more random and divergent than commuting activity [35]. The discriminated sized of activity spaces can reflect the spatial relationships among the different activity types. In general, the recreational activity space covers commuting activity space, and commuting activity space covers maintenance activity space.

In the time geography theory, activity space is determined not only by spatial dimension, but also the time allocation [7]. According to The 2018 National Time Utilization Survey [36], the statistical result of residents' time allocation is revealed and is just as shown in Figure 2 [36]. The time of physiologically necessary activity (including sleeping, personal health nursing, dining, etc.) accounted for $49.5 \%$ of residents' time. Paid work and unpaid work together possessed $29.6 \%$ of residents' time. The remaining time possession is mainly for discretionary activities $(16.4 \%)$, such as taking leisure or social interaction activities in places like shopping malls (public service places) or cinema (entertainment place). Transportation and study cost too little time to be the main activity; therefore, these two types of activity and working activity are combined together as commuting activity in this study.

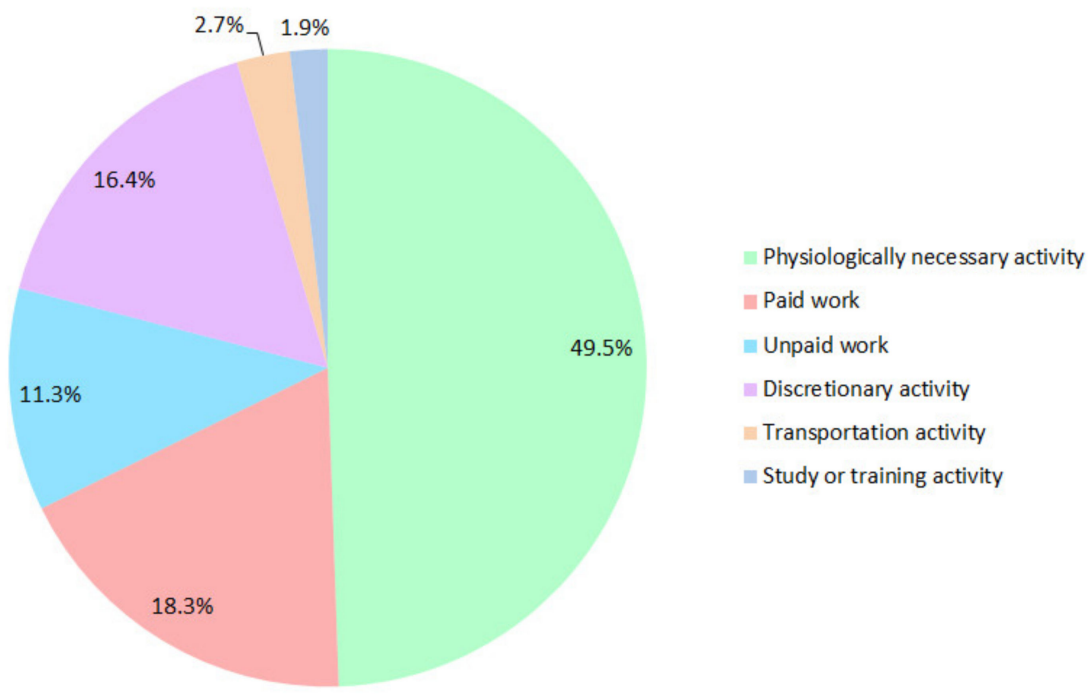

Figure 2. Time composition of residents' daily activities.

Maintenance activity is to meet the basic needs of residents, which coincides with the content of physiologically necessary activity. Therefore, the time (49.5\%) for physiologically necessary activity is considered the time for maintenance activity. For convenience of calculation, we define the maintenance activity space as the area that residents spend $50 \%$ of the time in their daily life (Figure 3). 
Commuting activity mainly refers to working, and the corresponding activity space is usually larger than the scope of maintenance activity space. The add-up time ratio for maintenance activity and commuting activity (paid work, unpaid work, transportation activity, and study or training activity) is 83.7\%. According to the description in The 2018 National Time Utilization Survey [36], the add-up time consumed for working activity includes a little work from home that needs to be subtracted. So we define the proximate time consuming for commuting and maintenance activities is $80 \%$ (close to $83.7 \%$ ) of residents' time in this study. As above, commuting activity space is the area that residents spend $80 \%$ of their time to reach in their daily lives (Figure 3).

Recreational activity refers to leisure, visiting friends, going on vacations and other related activities, which is discretionary activity mentioned in The 2018 National Time Utilization Survey [36]. Because the scale of recreational activity space covers the other two, excluding some unstated and accidental situations ( $5 \%$ of residents' time), the area that residents spend $95 \%$ of residents' time can be used as recreational activity space (Figure 3). Three quantiles, based on the time utilization survey, define the spatial scope of three types of activities. These activity spaces all participate in the regression analysis with corresponding built environment factors.

\subsection{Activity Space Identifying Algorithm}

We extract the main stopover point every half an hour from the mobile phone data of residents in data preprocessing. In order to identify the space for three types of activity, the resident's main stopover points in a period of time are arranged according to the distance to the residence, where the time duration at each point is equal, as shown in Figure 3. After accumulating the interval between adjacent spatio-temporal points in the distance ascending order, stopover points corresponding to $50 \%, 80 \%$ and $95 \%$ duration time can be extracted. As we mentioned earlier, a certain type of activity space is a certain area where residents spend corresponding time in their daily lives. According to the time ratio definition for three activity spaces in this study, the three stopover points extracted can represent the furthest location that residents have reached to complete three types of activities. For example, the maintenance activity space is made by the radius from residence to the blue point in Figure 3. In this research, the distance from stopover points extracted to the residence for each resident represents the scale of activity space.

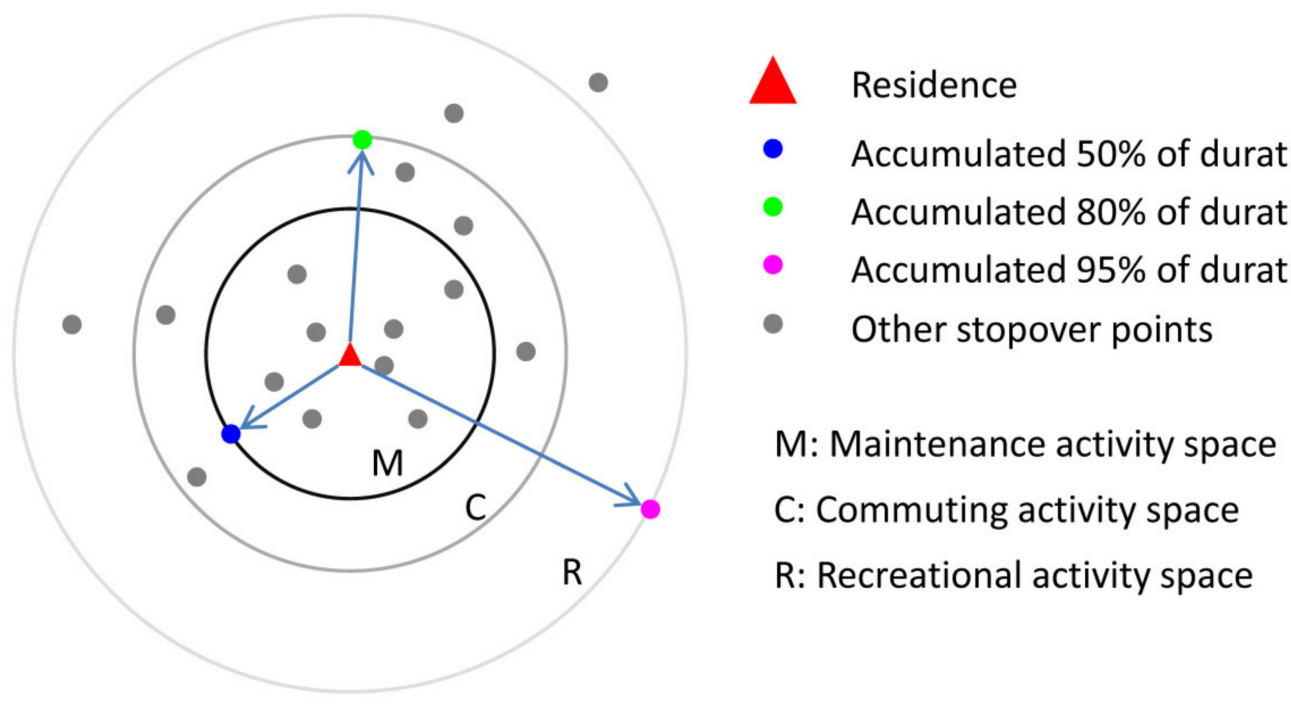

Figure 3. Definition of three activity spaces. Circle dots mean the main stopover points of residents. Three types of activity spaces have their own geographic scales, and they occupy different ratios of a lifetime. Therefore, the stopover point that accumulated the corresponding ratio of time represents the farthest place of that activity, and distance between the stopover point and home is the radius of that activity space. 
We consider the residence as the center of the activity space, identifying it as the top priority place of the resident. The entire study area is divided into Thiessen polygons created with the mobile phone service tower locations, as shown in Figure 1. The steps to determine the one's residence are as follows: (1) sum up one's footprints from 00:00 to 06:00 according to the service tower ID, (2) select the service tower that has the longest total stay time, (3) and take the service tower as the residence if the daily average of the longest total stay time during 00:00 and 06:00 at this tower is more than four hours. Due to the geometric characteristic of Thiessen polygons and the high density of the service tower, the coordinates of the service tower could represent the location of users' residences. If one's footprints are not enough to meet the recognition conditions, this user's data will be eliminated.

In order to obtain the scope of activity space, the resident's footprints are listed according to the distance between footprints and residence according to the ascending order of the distance value. Thus, three footprints of $50 \%, 80 \%$ and $95 \%$ quantiles are extracted in the order. The distances between the three footprints and residence represent the radii of maintenance activity space, commuting activity space, and recreational activity space respectively from the residence. All three ranges compose the scope of activity space in this paper. The complete identification process of individuals' activity space is shown in Figure 4. Since urban residents living in the same mobile phone tower service area share the same residence area, the residents' activity space radius is the average of the radius of all the residents' activity space in this service area.

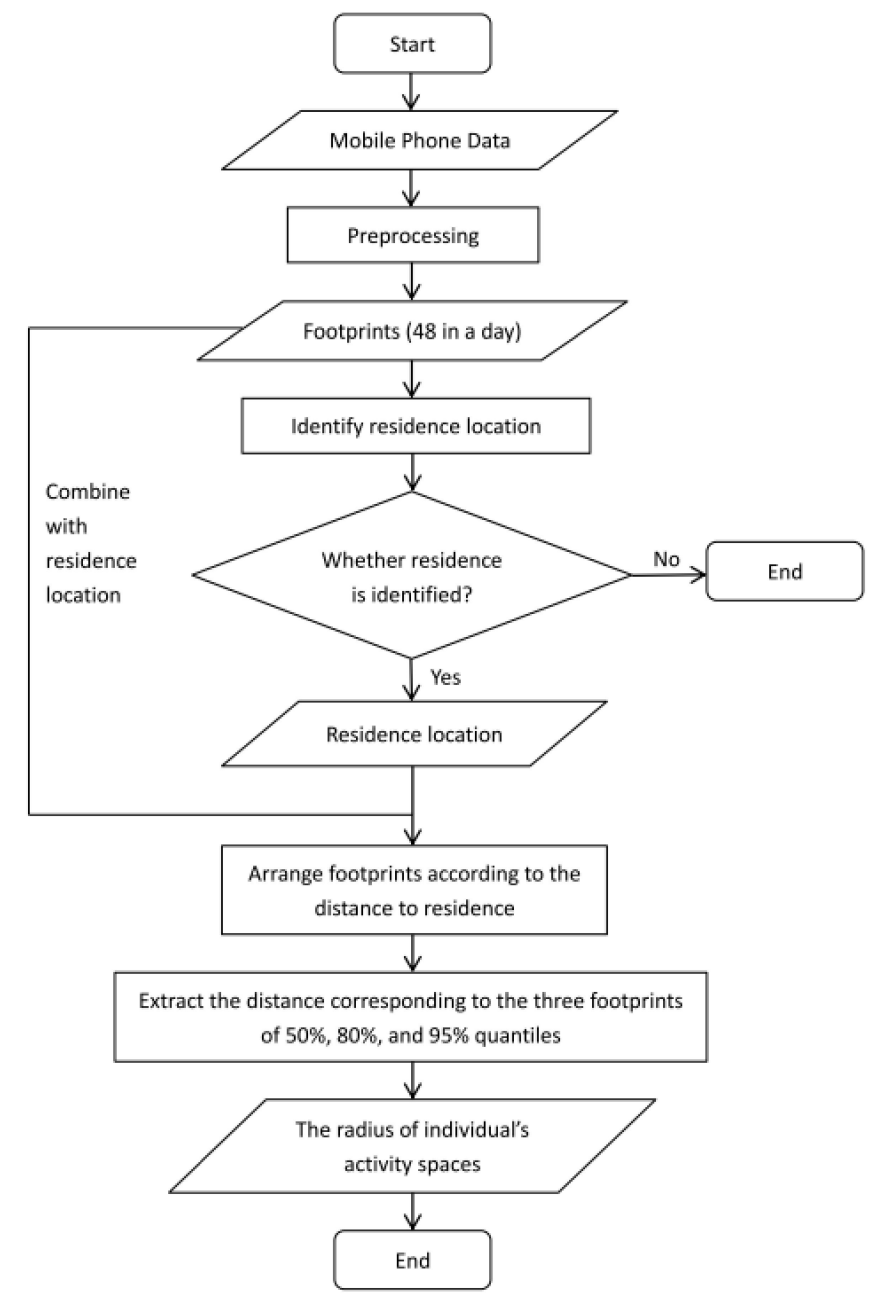

Figure 4. The flow of identifying an individual's activity spaces. 


\subsection{Correspondence between Activity Space and Built Environment}

Urban residents carry out different activities in different activity spaces. This is because each specific activity type requires distinguished functional places [9]. Consequently, there is a correlation between activity space and functional place. In this study, functional places are mainly identified by multiple categories of POI data (Table 1).

Urban residents mainly conduct catering, shopping, and sleeping at night in maintenance activity space. POI types closely related to these activities include Catering and Shopping subcategories in the Consumption primary category and the Residence category, as shown in Table 1 . When there are more related POIs around the residence, residents tend to complete these activities in a smaller spatial range. In commuting activity space, working, studying and commuting are defined as the major activity. So, Traffic, Education, and Corporation POIs correspond to commuting activity space. Moreover, some other factors affect the range of commuting activity space as well including the distance to the city center. The city center often represents convenience in transportation and job accessibility. Other than residence and commuting, people also need to have reached out for medical service, sports, entertainment, etc. to ensure and enrich their lives. These activities, defined as recreational activity, relate to multiple subcategories of POIs in the Consumption and Public service primary categories, such as Recreation and Comprehensive POIs.

Activity space represents the range of activities fulfilling the residents' various needs. Normally, residents prefer to consume as little time as possible to travel to their destinations. The variation of the built environment factors around the residence and the destinations is one of the main causes of the residents' travel [37]. The degree of associations between activities and functional places around residence has a direct impact on the activity space range. The spatial distribution of roads affects the time cost and travel trajectories of the residents' activities. Therefore, the transportation structure also has a significant impact on the residents' activity space.

Most studies adopted 5D factors (density, diversity, design, destination accessibility, and distance to transit) as built environment factors $[17,38-40]$. Density and diversity describe the comprehensive facility distribution around residents' target locations. Design, destination accessibility, and distance to transit directly or indirectly represent the characteristics and properties of the transportation system. Density and diversity can be represented by land-use data. In this paper, POI data is used to replace land use data because, compared to land use data, POI data can describe the function and location of urban space entity facilities more distinct and plentiful. Other built environment factors are represented by other types of data, such as road network density, distance to the city center, etc.

POI data and other types of data are combined to form independent variables. Density factors can refer to population density, job density, or volume rate, etc. In this study, different types of POIs density in activity space are used to represent homologous functional places' density in the activity space,

$$
\text { POI density }=n / s,
$$

where $n$ is the number of different types of POI in the activity space and $s$ is the area of the activity space.

The diversity is usually characterized by the degree of land use mixture and illustrates the possibility of meeting the needs of various activities. POI diversity is calculated as

$$
\text { POI diversity }=-\frac{\left(\sum_{i=1}^{N} p_{i} \ln p_{\mathrm{i}}\right)}{\ln N}, p_{i}=\frac{d_{i}}{D^{\prime}}
$$

where $N$ is the number of POI species and $p_{i}$ is equal to the relative density of type $i$ POI divided by the sum of the relative density of all types POI in the activity space; $d_{i}$ is the relative density of type $i$ POI and is equal to the density of type $i$ POI in the activity space divided by the density of type $i$ POI in Zhuhai, $D$ is the sum of $d_{i}$.

Average block size, road network density, and the number of intersections of roads in each spatial unit are usually used to measure the design variable. The road network is one of the most important 
data of urban design and is often called the urban artery that carries the flow of people and goods. In this research, road network density represents the design variable, and it is calculated as

$$
\text { POI Road network density }=\frac{l}{s},
$$

where $l$ is the length of road in the activity space and $s$ is the area of the activity space.

The destination accessibility variable represents the convenience of traveling from orientation to destination. It refers to the distance to the city center or central business district (CBD) in the urban region. We take distance to city center as the variable, calculated as the distance between mobile phone service tower and city center.

In addition, we introduce working population density as an independent variable to represent job density, replacing Corporation. Corporation could not represent all the job locations given that many other types of POI can also be the working place. For example, for employees in shops, shopping POI is their working place. So we define working population density independently to represent job opportunities. It is worth noting that working population density is calculated by mobile phone data in the way of identifying people's working place (mobile phone service area), which is similar to identifying people's residences. And there are many different subcategories of recreational activities, some of which are not for entertainment.

The main factors related to activity vary due to the types of activities. According to the discussion in Section 3.1, maintenance activity space occupies 50\% of the residents' living time. Its spatial range contains the activities to meet the basic living needs of the residents. Based on the activity type and built environmental factors, the variables of Catering, Shopping, Residence, POI diversity, road network density, and distance to city center normally have an impact on the radius of maintenance activity. Similarly, factors that may relate to commuting and recreational activity space are also chosen and shown in Table 2.

Table 2. Variables in three regression models.

\begin{tabular}{cccc}
\hline Variables & Model 1 & Model 2 & Model 3 \\
\hline & (Maintenance) & (Commuting) & (Recreational) \\
\hline Catering & $\sqrt{ }$ & - & - \\
Shopping & $\sqrt{ }$ & - & - \\
Recreation & - & - & $\sqrt{ }$ \\
Comprehensive & - & - & $\sqrt{ }$ \\
Public facility & - & - & - \\
Educational and scientific service & - & $\sqrt{ }$ & - \\
Residence & $\sqrt{ }$ & $\sqrt{ }$ & $\sqrt{ }$ \\
POI diversity & $\sqrt{ }$ & $\sqrt{ }$ & - \\
Distance to city center & $\sqrt{ }$ & - & - \\
Road network density & $\sqrt{ }$ & $\sqrt{ }$ & $\sqrt{ }$ \\
Working population density & - & &
\end{tabular}

In order to gain a better understanding of the correlation between these factors and activity space, we use the above variables as independent variables and the radius of activity space as a dependent variable, multiple linear regressions are performed [23,41].

\section{Empirical Study}

\subsection{Activity Space Identification Result}

Mobile phone data is processed using the method we mentioned in Section 3.1, and the result of the activity space identification is shown in Figure 5. For the residents living in a mobile phone tower service area, their activity space size is measured as the spatial area with their average radius of 
activity space. Some residents might not have a job or do not need to commute. In order to improve the identification result, we proposed a filtering method to identify the working residents. The resident who stays in his working area for more than four hours every day is considered a working resident.

As shown in Figure 5a, the radius of maintenance activity space is less than 2500 meters in most areas. Residents of Xiangzhou District, the core area of Zhuhai, mainly live in the maintenance activity space that is below 1000 meters, and only the northeast of this district has a larger activity space. The radius of maintenance activity space in Doumen District and Jinwan District is mainly between 1000 meters and 2500 meters, but a few of them are lower or higher than this range. In commuting activity space shown in Figure 5b, the radius of commuting activity space in Xiangzhou District is mainly within 2000 meters and still better than another two. The distributions of the radius of commuting activity space in Doumen District and Jinwan District are similar. Most areas of the two districts have the radius of commuting activity space between 2000 meters and 4000 meters. And in recreational activity space, the difference of the radius is dramatic, just as shown in Figure 5c. In Xiangzhou District, recreational activities can be satisfied within 5000 meters normally. But in Doumen District and Jinwan District, more than half of areas need to travel more than 7500 meters to complete recreational activities. And only a few central areas of the two districts have the radius of recreational activities like Xiangzhou District.

The results indicate that the density and spatial distribution of facilities influence the recreational activity space size more substantial than the other two types of activities. Their influence on the maintenance activity space is the least evident.

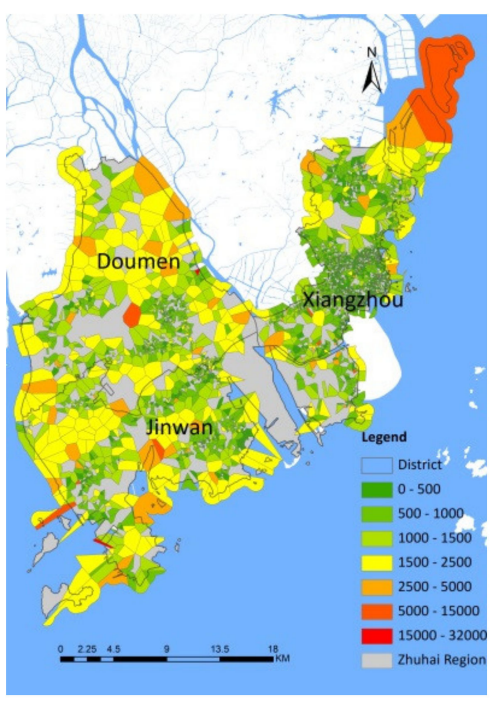

(a)

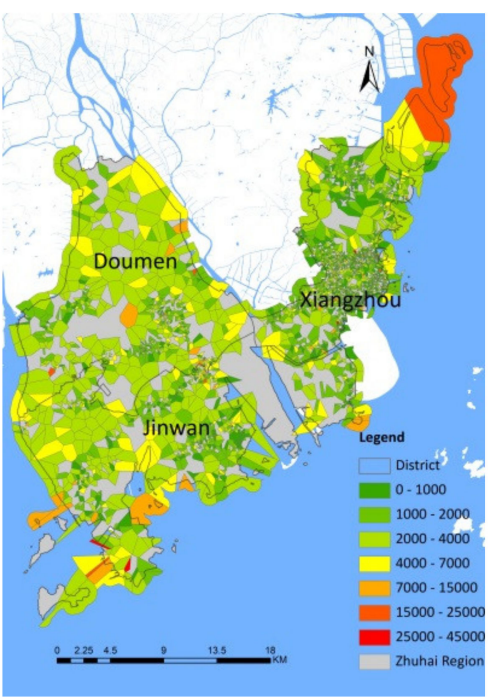

(b)

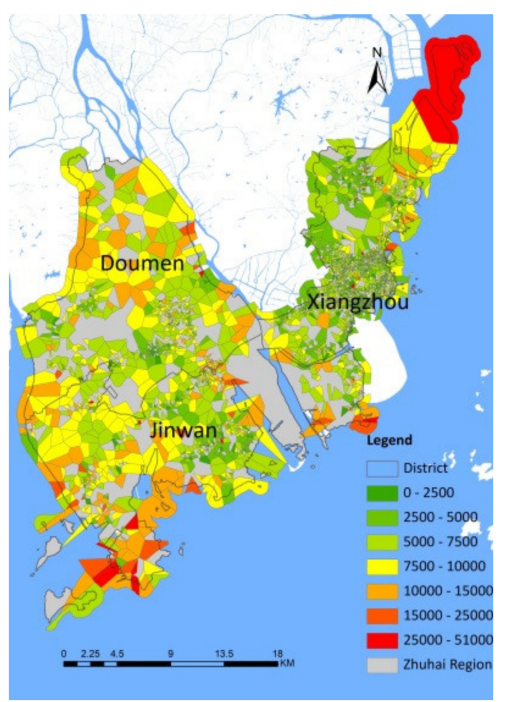

(c)

Figure 5. The radius of activity space in the mobile phone tower service areas. (a) Maintenance activity space; (b) Commuting activity space; (c) Recreational activity space.

\subsection{Built Environment Factors and the Regression Model}

Every mobile phone tower service area has three scales of activity spaces in the form of a circle. Variables of built environment factors are calculated in three scales of activity space, and the statistical characteristics of these variables are shown in Table 3. The distribution of some variables in commuting activity space is shown in Figure 6. 
Table 3. Descriptive statistics of independent variables.

\begin{tabular}{ccccccc}
\hline Variables & \multicolumn{2}{c}{ Model 1 } & \multicolumn{2}{c}{ Model 2 } & \multicolumn{2}{c}{ Model 3 } \\
\hline & Mean & Std. & Mean & Std. & Mean & Std. \\
\hline Catering & 125.944 & 227.684 & 73.901 & 125.575 & 51.676 & 94.139 \\
Shopping & 247.603 & 737.304 & 137.854 & 297.888 & 96.012 & 187.692 \\
Recreation & 16.697 & 29.084 & 10.353 & 16.288 & 7.104 & 10.681 \\
Comprehensive & 15.037 & 38.174 & 8.799 & 17.798 & 5.965 & 12.159 \\
Public facility & 3.538 & 7.863 & 2.315 & 4.260 & 1.641 & 3.282 \\
Educational and- & 22.442 & 42.756 & 14.121 & 24.733 & 10.065 & 17.326 \\
Scientific service & 18.897 & 32.632 & 11.403 & 21.070 & 8.185 & 18.233 \\
$\quad$ Residence & 0.067 & 0.040 & 0.074 & 0.024 & 0.075 & 0.017 \\
POI Diversity & 16.889 & 14.733 & 16.889 & 14.733 & 16.889 & 14.733 \\
Distance to city- & \multirow{2}{*}{5.839} & 5.188 & 67.326 & 733.822 & 3.727 & 2.640 \\
Center & 125.944 & 227.684 & 73.901 & 125.575 & 51.676 & 94.139 \\
Road network density & & & & & &
\end{tabular}

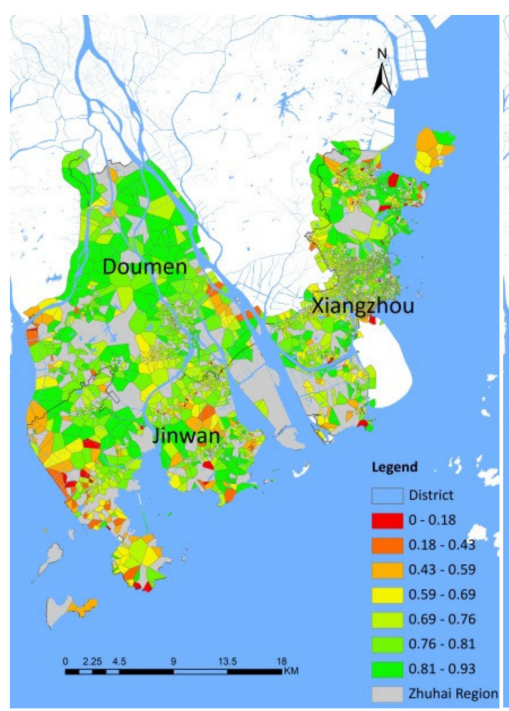

(a)

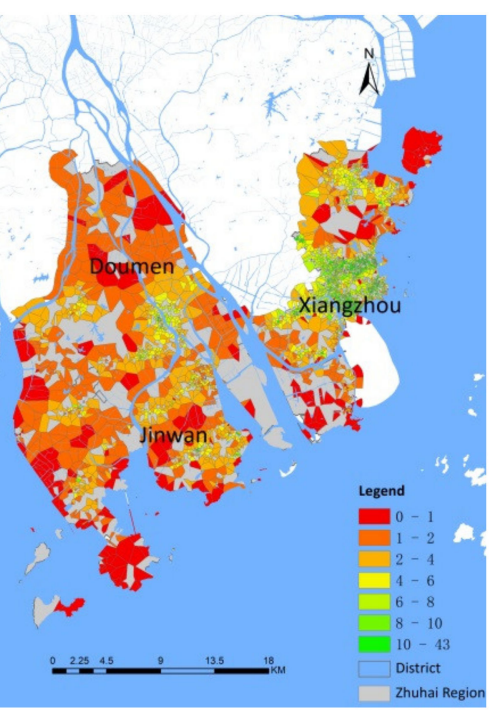

(b)

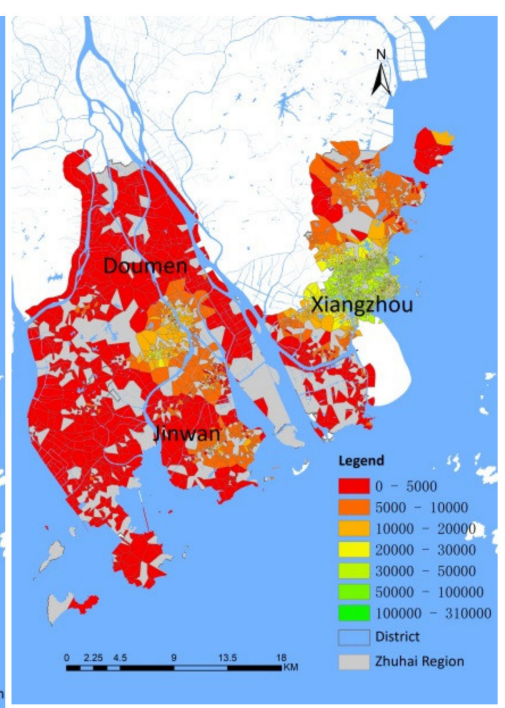

(c)

Figure 6. The distribution of three variables in Commuting activity space. (a) POI diversity; (b) road density $\left(\mathrm{km} / \mathrm{km}^{2}\right)$; (c) working population density $\left(/ \mathrm{km}^{2}\right)$.

Three models were designed and applied to examine the relationship between built environment factors and activity space, and the results are reported in Table $4 . R^{2}$ of three models are $0.514,0.524$, and 0.458, which illustrates that the three models fit the relationship between built environment factors and activity space. Variance inflation factor (VIF) is an indicator of the severity of collinearity in a multiple linear regression model, and when the VIF values are less than 10, collinearity is not statistically significant. Expect a VIF value of Recreation (10.104) in model 3, the VIF values of variables in these models shown in Table 5 are obviously less than 10. This result indicates that there is no collinearity among these explanatory variables. The standardization coefficients and significant value in the model can reveal the significant factors for activity space size and their influence degree.

The result of Model 1 (Table 4) shows the significance of each built environment factor in maintenance activity space and the influence coefficient on the radius of it. The probability $P$ values of the built environment factors of maintenance activity space are shown in Table 4 . According to the given significant level of 0.05 , these factors, including Catering, Shopping, Residence, etc., are significantly related to the radius of maintenance activity space in Model 1. So, these factors significantly affect 
the range of activity space. Catering, Shopping, Residence, and road network density are negatively correlated with the radius of maintenance activity space. The coefficients of POI diversity and distance to city center are positive. When these factors increase, the range of activity space becomes larger. However, a bigger activity space is not good for living convenience.

The result of Model 2 (Table 4) shows the result of commuting activity space. According to the significant level of 0.05 , these factors, including educational and scientific service, working population density, POI diversity, distance to city center, and road network density, are significantly related to the radius of commuting activity space, meaning that these factors significantly affect the size of commuting activity space. Educational and scientific service and road density are negatively correlated with the radius of commuting activity space. The coefficients of working population density, POI diversity, and distance to city center are positive.

The result of Model 3 (Table 4) demonstrates the analysis result for recreational activity space. It shows that Recreation, Comprehensive, POI diversity, and public facility have a significant impact on the radius of recreational activity space. Among these factors, the larger Recreation and Comprehensive, the smaller the radius of recreational activity space is, while POI diversity and public facility are the opposite.

Table 4. Regression results on the relationship between built environment factors and activity space.

\begin{tabular}{|c|c|c|c|}
\hline Model & Standardization Coefficient & Sig. & Adjust $R^{2}$ \\
\hline \multicolumn{4}{|l|}{ Model 1 (Maintenance) } \\
\hline Catering & -0.047 & 0.010 & \multirow{6}{*}{0.514} \\
\hline Shopping & -0.059 & 0.000 & \\
\hline Residence & -0.111 & 0.000 & \\
\hline POI Diversity & 0.354 & 0.000 & \\
\hline Distance to city center & 0.255 & 0.000 & \\
\hline Road network density & -0.434 & 0.000 & \\
\hline \multicolumn{4}{|l|}{ Model 2 (Commuting) } \\
\hline $\begin{array}{l}\text { Educational and- } \\
\text { scientific service }\end{array}$ & -0.088 & 0.000 & \multirow{5}{*}{0.524} \\
\hline $\begin{array}{l}\text { Working population- } \\
\text { density }\end{array}$ & 0.085 & 0.000 & \\
\hline POI diversity & 0.443 & 0.000 & \\
\hline Distance to city center & 0.095 & 0.000 & \\
\hline Road network density & -0.517 & 0.000 & \\
\hline \multicolumn{4}{|l|}{ Model 3 (Recreational) } \\
\hline Recreation & -0.394 & 0.000 & \multirow{5}{*}{0.458} \\
\hline Comprehensive & -0.212 & 0.000 & \\
\hline POI Diversity & 0.440 & 0.000 & \\
\hline Distance to city center & 0.012 & 0.422 & \\
\hline Public facility & 0.287 & 0.000 & \\
\hline
\end{tabular}

In three models, the variable POI diversity is significantly but positively related to the radius of activity space, which means the higher the POI diversity, the larger the activity space. This is not consistent with existing research. For example, Cervero concluded that increasing the land use diversity can reduce the possibility of long-distance commuting activities [21]. 
Table 5. Variance inflation factor (VIF) values of three regression models.

\begin{tabular}{|c|c|c|c|c|c|}
\hline \multicolumn{2}{|c|}{ Model 1} & \multicolumn{2}{|c|}{ Model 2} & \multicolumn{2}{|l|}{ Model 3} \\
\hline Variables & VIF & Variables & VIF & Variables & VIF \\
\hline Catering & 2.262 & $\begin{array}{l}\text { Educational and- } \\
\text { scientific service } \\
\text { Working }\end{array}$ & 1.005 & Recreation & 10.104 \\
\hline Shopping & 1.620 & $\begin{array}{l}\text { population- } \\
\text { density }\end{array}$ & 2.120 & Comprehensive & 3.244 \\
\hline Residence & 1.217 & POI density & 1.027 & Diversity & 1.153 \\
\hline POI density & 1.046 & $\begin{array}{l}\text { Distance to city } \\
\text { center }\end{array}$ & 1.912 & Distance to city center & 1.292 \\
\hline $\begin{array}{l}\text { Distance to- } \\
\text { city center }\end{array}$ & 1.343 & Road density & 1.659 & Public facility & 6.100 \\
\hline Road density & 1.722 & & & & \\
\hline
\end{tabular}

\subsection{Discussion}

According to the explanation in Section 3, maintenance activity space is the scope of activities that meet the basic needs of the residents, mainly includes the residence and its surrounding areas. For maintenance activity space, it is considered that the Catering, Shopping, Residence, POI diversity, road network density, and distance to the city center may have an impact on the radius. As expected, the model 1 shows that these independent variables are significantly related to the size of maintenance activity space, because these six variables are relevant to the basic needs of residents.

Catering, Shopping, Residence, and road network density are negatively related to the radius of activity space, which means that these built environments are the main reasons that maintenance activity takes place. So people living around these functional places can enjoy smaller maintenance activity space. With many of these facilities around the residence, people do not need to travel far to fulfill the basic living needs such as grocery or catering. Distance to city center is positively related to the activity space. Zhuhai is a monocentric city, and the density of the built environment is gradually reduced when the distance to the urban center increases. The amount of facilities is insufficient in the region far from the city center. Thus, the residents have to go to further places to complete their living activities. As a result, the radius of activity space increases.

In commuting activity space, residents mainly work or study, and commute between places of working/studying and home. Therefore, commuting activity space is an area related to working population density and educational and scientific service. Working population density and distance to city center are positively related to the size of commuting activity space. City center often equipped with kinds of facilities related to numerous job opportunities. The city center can also be considered a working center. The overall situation is that the closer to city center, the shorter commuting distance is. In other words, the radius of commuting activity space increase when Distance to city center increases. Educational and scientific service and road density have a negative impact on commuting activity space. Educational and scientific service provides places for studying activity. The more it is, the smaller the commuting range. Road density reflects the convenience of transportation which can effectively reduce commuting time. In the time geography perspective, less time for commuting also means smaller activity space.

Recreational activity space is the area where enjoying leisure, visiting friends, going on vacations and other related activities take place. In our assumption, Recreation, Comprehensive, Distance to city center, Public facility has an impact on the size of recreational activity space. City center is generally considered as the center of working. Distance to city center isn't significantly related to activity space size because they don't match the recreational activity. Recreation and Comprehensive are significantly and negatively related to the size of recreational activity space. Moreover, in the two POI density factors, Recreation has a more important influence on recreational activity space than Comprehensive. This also illustrates that the recreation activity is the main type of activity in recreational activity 
space and has a greater impact than the comprehensive activity. Due to the obvious differences in functions, the density of places related to recreational activity is relatively low in places with dense public facilities. Therefore, public facility is positively related to the size of recreational activity space.

As a result, the positive related relationship between POI diversity and the size of activity space was much different from existing research. This is mainly owed to the varying size of the activity space defined by the average radius of the activity spaces of all residents living in the spatial unit. When sizes of the spatial units are the same or similar, a low diversity will lead to a long travel distance because residents tend to find more facilities to fulfill the daily life, which has been verified by a large amount of existing research [42]. In this paper, the ranges of the spatial units (activity space in this research) depend on the average radius of activities and the built environment indexes are measured on the spatial units with varying radius. In this way, the range of activity space is consistent with that of built environment. Therefore, residents in a fixed range and low diversity area will tend to extend the activity space to find more types of facilities to fulfill the various requirements in daily life. Another reason leading to the positive relationship between POI-based diversity and activity radius is the directionality of residents' activity. Yuan and Raubal have proved that the directionality of residents' daily life [29]. When residents tend to find more facilities in one direction in a broader range, the amount and types of POIs will quickly increase and lead to the positive relationship between POI diversity and size of activity space (Figure 7).

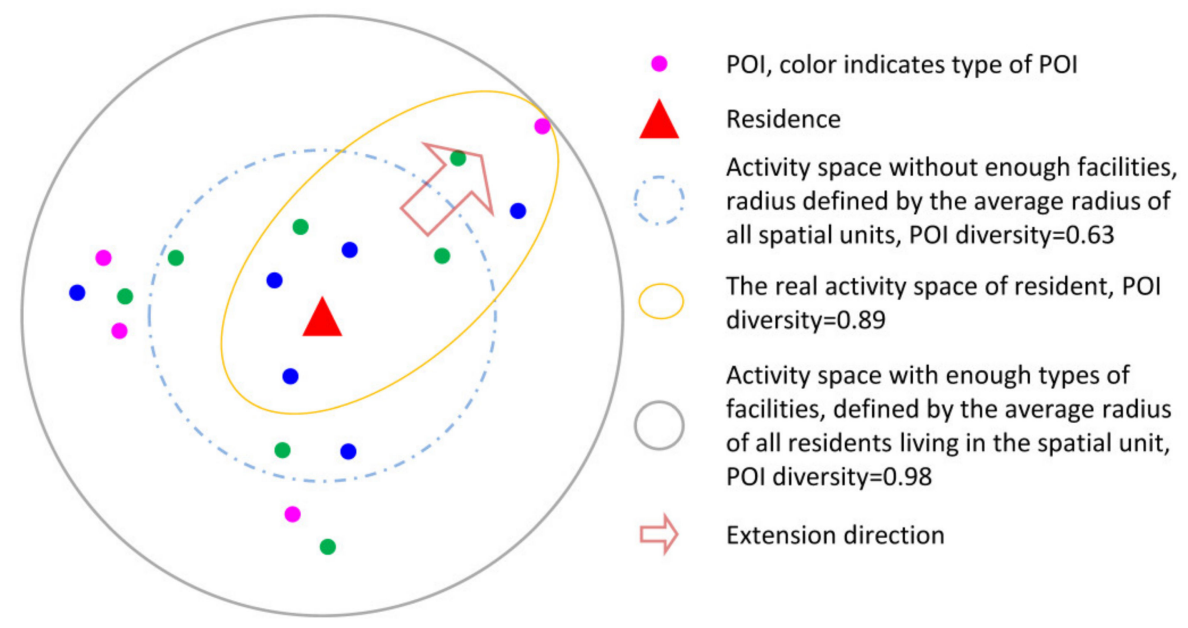

Figure 7. The directional extension of activity space leads to high POI diversity and large activity space.

To verify this assumption, we calculate built environment factors in a fixed range, taking the average activity space of all mobile phone tower service area as the spatial unit to calculate built environment indexes. Using the new statistical result of built environment factor as an independent variable, the true radius of activity space as a dependent variable can examine the relationship between POI diversity and activity space. As shown in Table 6, in the regression result, the coefficients are all negative value and significance values are all below 0.05 . That means POI diversity has a significant and negative relationship with activity space indeed when a fixed range of the spatial units is adopted.

Table 6. The regression results of the three models when POI diversity is calculated with a fixed range of the spatial units.

\begin{tabular}{ccc}
\hline Model & Coefficient & Sig. \\
\hline Maintenance activity space & -0.618 & 0.000 \\
Commuting activity space & -1.413 & 0.000 \\
Recreational activity space & -1.363 & 0.000 \\
\hline
\end{tabular}


Mobile phone data is aplenty and accurate in urban areas and the method based on mobile phone data can be applied in other cities. As we mentioned before, this method can identify the address of mobile phone users, and then we get the population density of each space unit. In the ideal state of resource allocation, the higher the population density, the smaller the activity space. Hence, we are able to divide sizes of expected activity spaces into several levels according to the population density, and also can divide the identified actual activity spaces of residents into the same levels. In the comparison of active spaces in two states, we can find some noteworthy situations. For example, the expected maintenance active space level is smaller than the actual one, which means that facilities related to maintenance activities need to be improved in the area, while the expected commuting activity space is smaller than the real one according to the mobile phone data. Therefore, the planners can investigate the job-housing balance of the district and propose strategies to reduce the commuting distance. The comparison of different activity spaces and different comparison situations can help planners carry out urban planning.

\section{Conclusions}

Activity space is a reflection of human lifestyle and living patterns. The spatial characteristics (e.g., the size of the area or the geographical location) vary among different activity types. The discrimination for activity spaces for multiple activity types is crucial for understanding urban life. However, multi-type activity spaces are seldom discussed in previous research. Also, the researchers have not paid much attention to the activity space measuring method. This study focuses on these limitations on activity space research. We aim at discovering the residents' activity space for multiple activity types and understanding the activity space formation patterns in different spatio-temporal scales.

The contribution of this study mainly lies in three aspects:

1. We propose a multiple geographic scale activity space measuring method using the temporal duration of activities on the top of Time Geography theory and apply the massive mobile phone data on discovering the activity space at multiple geographic scales according to activity types. Using this method, the human activity space for multiple activities can be accurately captured and depicted. We also demonstrate the proposed method using Zhuhai mobile phone data.

2. We analyze the relationship between activity space size and the built environment in detail at multiple geographic scales in Zhuhai. We find that different types of land-use affect the size of activity space differently. We also discover the positive relationship between POI diversity and the size of activity space at each geographic scale, which was much different from existing studies. This may be owed to the varying size of activity spaces defined by the average radius of the activity spaces of residents living in the spatial unit.

3. In general, this research provides a method for measuring human activity space and can reveal the spatio-temporal characteristics of urban activities. For example, this method can identify areas with large activity space and dense population, which means that these areas need to build more functional facilities. Also, the findings from these results offer a better understanding of the relationships between the urban activity and the built environment at multiple geographic scales, revealing the main environmental factors that need to be built or improved. These can facilitate the urban planner to ameliorate the facility distributions for improving citizens' life quality.

Some other issues are worth exploring in-depth in this study. For example, how seasons affect activity space has not been discussed, and the effect of seasonality in travel behavior should be considered in future work.

Author Contributions: Conceptualization, Y.G. and Y.L.; Methodology, Y.G. and Y.L.; Formal Analysis, L.G., M.J. and Q.L.; Investigation, L.G. and Q.L.; Data Curation, L.G., M.J., Q.L. and Y.G.; Writing-Original Draft Preparation, L.G. and Q.L.; Writing-Review \& Editing,, L.G., M.J. and Y.G.; Visualization, M.J.; Supervision, Y.G. and Y.L.; Project Administration, Y.G.; Funding Acquisition, Y.G. and Y.L. All authors have read and agreed to the published version of the manuscript. 
Funding: This research was funded by the National Key Research and Development Program of China (2017YFE0196100), the National Natural Science Foundation of China (41830645, 41771169), the Techhand Open Fund of Laboratory for Urban Future, Peking University (Shenzhen) ( 201703), and the Open Research Fund Program of Shenzhen Key Laboratory of Spatial Smart Sensing and Services (Shenzhen University).

Acknowledgments: We would like to thank Dr. Yihong Yuan for her helpful suggestions.

Conflicts of Interest: The authors declare no conflict of interest.

\section{References}

1. Golledge, R.G.; Stimson, R.J. Spatial Behavior: A Geographic Perspective; The Guilford Press: New York, NY, USA, 1997; pp. 277-282.

2. Sherman, J.E.; Spencer, J.; Preisser, J.S.; Gesler, W.M.; Arcury, T.A. A suite of methods for representing activity space in a healthcare accessibility study. Int. J. Health Geogr. 2005, 4, 24. [CrossRef] [PubMed]

3. Vallée, J.; Cadot, E.; Grillo, F.; Parizot, I.; Chauvin, P. The combined effects of activity space and neighbourhood of residence on participation in preventive health-care activities: The case of cervical screening in the paris metropolitan area (france). Health Place 2010, 16, 838-852. [CrossRef] [PubMed]

4. Palmer, J.R.B. Activity-Space Segregation: Understanding Social Divisions in Space and Time. Ph.D. Thesis, Princeton University, Princeton, NJ, USA, 2013.

5. Mason, M.J. Attributing activity space as risky and safe: The social dimension to the meaning of place for urban adolescents. Health Place 2010, 16, 926-933. [CrossRef] [PubMed]

6. Kestens, Y.; Lebel, A.; Chaix, B.; Clary, C.; Daniel, M.; Pampalon, R.; Theriault, M.; Subramanian, S.V. Association between activity space exposure to food establishments and individual risk of overweight. PLoS ONE 2012, 7, e41418. [CrossRef]

7. Hägerstrand, T. What about people in regional science? Pap. Reg. Sci. Assoc. 1970, 24, 6-21. [CrossRef]

8. Congrès International d'Architecture Modern. Charter of Athens. In Proceedings of the 4th meeting of CIAM, Athens, the Hellenic Republic, 29 July-31 August 1933.

9. Handy, S.L.; Boarnet, M.G.; Ewing, R.; Killingsworth, R.E. How the built environment affects physical activity: Views from urban planning. Am. J. Prev. Med. 2002, 23, 64-73. [CrossRef]

10. Yang, L.; Hu, L.; Wang, Z. The built environment and trip chaining behaviour revisited: The joint effects of the modifiable areal unit problem and tour purpose. Urban Stud. 2019, 56, 795-817. [CrossRef]

11. Golledge, R.G. Learning about urban environments. In Timing Space and Spacing Time; Parkes, D.N., Thrift, N., Eds.; Edward Arnold: London, UK, 1978.

12. Bagrow, J.P.; Koren, T. Investigating bimodal clustering in human mobility. In Proceedings of the International Conference on Computational Science and Engineering, Vancouver, BC, Canada, 29-31 August 2009; Volume 4, pp. 944-947.

13. Kutter, E. A model for individual travel behaviour. Urban Stud. 1973, 10, 235-258. [CrossRef]

14. Roof, K.; Oleru, N. Public health: Seattle and King County's push for the built environment. J. Environ. Health 2008, 71, 24-27.

15. Boarnet, M.; Crane, R. The influence of land use on travel behavior: Specification and estimation strategies. Transp. Res. Part A Policy Pract. 2001, 35, 823-845. [CrossRef]

16. Cervero, R.; Kockelman, K. Travel demand and the 3Ds: Density, diversity, and design. Transp. Res. Part D Transp. Environ. 1997, 2, 199-219. [CrossRef]

17. Cao, X.J.; Mokhtarian, P.L.; Handy, S.L. The relationship between the built environment and nonwork travel: A case study of Northern California. Transp. Res. Part A Policy Pract. 2009, 43, 548-559. [CrossRef]

18. Pushkar, A.O.; Hollingworth, B.J.; Miller, E.J. A multivariate regression model for estimating greenhouse gas emissions from alternative neighborhood designs. In Proceedings of the 79th Annual Meeting of the Transportation Research Board, Washington, DC, USA, 9-13 January 2000.

19. Haybatollahi, M.; Czepkiewicz, M.; Laatikainen, T.; Kyttä, M. Neighbourhood preferences, active travel behaviour, and built environment: An exploratory study. Transp. Res. Part F Traffic Psychol. Behav. 2015, 29, 57-69. [CrossRef]

20. Alfonzo, M.; Boarnet, M.G.; Day, K.; Mcmillan, T.; Anderson, C.L. The relationship of neighbourhood built environment features and adult parents' walking. J. Urban Des. 2008, 13, 29-51. [CrossRef] 
21. Cervero, R. Built environments and mode choice: Toward a normative framework. Transp. Res. Part D Transp. Environ. 2002, 7, 265-284. [CrossRef]

22. Levinson, D.M.; Kumar, A. Density and the journey to work. Growth Chang. 1997, 28, 147-172. [CrossRef]

23. Schwanen, T. The impact of metropolitan structure on commute behavior in the netherlands: A multilevel approach. Growth Chang. 2010, 35, 304-333. [CrossRef]

24. Moilanen, M. Matching and settlement patterns: The case of norway. Pap. Reg. Sci. 2010, 89, $607-623$. [CrossRef]

25. Schwanen, T.; Ettema, D.; Timmermans, H. If you pick up the children, I'll do the groceries: Spatial differences in between-partner interactions in out-of-home household activities. Environ. Plan. A 2007, 39, 2754-2773. [CrossRef]

26. Xu, Y.; Shaw, S.L.; Zhao, Z.; Yin, L.; Fang, Z.; Li, Q. Understanding aggregate human mobility patterns using passive mobile phone location data: A home-based approach. Transportation 2015, 42, 625-646. [CrossRef]

27. Kang, C.; Liu, Y.; Ma, X.; Wu, L. Towards estimating urban population distributions from mobile call data. J. Urban Technol. 2012, 19, 3-21. [CrossRef]

28. Xu, Y.; Shaw, S.L.; Zhao, Z.; Yin, L.; Lu, F.; Chen, J.; Fang, Z.; Li, Q. Another tale of two cities: Understanding human activity space using actively tracked cellphone location data. Ann. Am. Assoc. Geogr. 2016, 106, 489-502.

29. Yuan, Y.; Raubal, M. Analyzing the distribution of human activity space from mobile phone usage: An individual and urban-oriented study. Int. J. Geogr. Inf. Sci. 2016, 30, 1594-1621. [CrossRef]

30. Calabrese, F.; Diao, M.; Di Lorenzo, G.; Ferreira, J., Jr.; Ratti, C. Understanding individual mobility patterns from urban sensing data: A mobile phone trace example. Transp. Res. Part C Emerg. Technol. 2013, 26, 301-313. [CrossRef]

31. Saelens, B.E.; Handy, S.L. Built environment correlates of walking: A review. Med. Sci. Sports Exerc. 2008, 40, S550. [CrossRef]

32. Yue, Y.; Zhuang, Y.; Yeh, A.G.O.; Xie, J.Y.; Ma, C.L.; Li, Q.Q. Measurements of poi-based mixed use and their relationships with neighbourhood vibrancy. Int. J. Geogr. Inf. Sci. 2017, 31, 658-675. [CrossRef]

33. Srinivasan, S.; Bhat, C.R. Modeling household interactions in daily in-home and out-of-home maintenance activity participation. Transportation 2005, 32, 523-544. [CrossRef]

34. Schönfelder, S.; Axhausen, K.W. Activity spaces: Measures of social exclusion? Transp. Policy 2003, 10, 273-286. [CrossRef]

35. Ham, S.A.; Kruger, J.; Tudor-Locke, C. Participation by US adults in sports, exercise, and recreational physical activities. J. Phys. Act. Health 2009, 6, 6-14. [CrossRef]

36. Bureau of Statistics of China. The 2018 National Time Utilization Survey Bulletin. China Statistics 2019, 2, $10-14$.

37. Ren, M.; Lin, Y.; Jin, M.; Duan, Z.; Gong, Y.; Liu, Y. Examining the effect of land-use function complementarity on intra-urban spatial interactions using metro smart card records. Transportation 2019. [CrossRef]

38. Shiftan, Y.; Barlach, Y. Effect of employment site characteristics on commute mode choice. Transp. Res. Rec. 2002, 1781, 19-25. [CrossRef]

39. Zhang, M. The role of land use in travel mode choice: Evidence from Boston and Hong Kong. J. Am. Plan. Assoc. 2004, 70, 344-360. [CrossRef]

40. Greenwald, M.J.; Boarnet, M.G. Built environment as determinant of walking behavior: Analyzing nonwork pedestrian travel in Portland, Oregon. Transp. Res. Record. 2001, 1780, 33-41. [CrossRef]

41. Bichler, G.; Christie-Merrall, J.; Sechrest, D. Examining juvenile delinquency within activity space: Building a context for offender travel patterns. J. Res. Crime Delinq. 2011, 48, 472-506. [CrossRef]

42. Boussauw, K.; Neutens, T.; Witlox, F. Relationship between spatial proximity and travel-to-work distance: The effect of the compact city. Reg. Stud. 2012, 46, 687-706. [CrossRef]

(C) 2020 by the authors. Licensee MDPI, Basel, Switzerland. This article is an open access article distributed under the terms and conditions of the Creative Commons Attribution (CC BY) license (http://creativecommons.org/licenses/by/4.0/). 